\title{
Effects of Fe Impurities on Self-Discharge Performance of Carbon-Based Supercapacitors
}

\author{
Yuting Du ${ }^{1}$, Yan $\mathrm{Mo}^{1}$ and Yong Chen ${ }^{1,2, *}$ \\ 1 State Key Laboratory of Marine Resource Utilization in South China Sea, Hainan Provincial Key Laboratory \\ of Research on Utilization of Si-Zr-Ti Resources, Hainan University, Haikou 570228, China; \\ 18080500210005@hainanu.edu.cn (Y.D.); moy0128@mail.nwpu.edu.cn (Y.M.) \\ 2 Guangdong Key Laboratory for Hydrogen Energy Technologies, School of Materials Science and Hydrogen \\ Energy, Foshan University, Foshan 528000, China \\ * Correspondence: ychen2002@163.com; Tel.: +86-898-66259513
}

Citation: Du, Y.; Mo, Y.; Chen, Y. Effects of Fe Impurities on Self-Discharge Performance of Carbon-Based Supercapacitors. Materials 2021, 14, 1908.

https://doi.org/10.3390/ma14081908

Academic Editor: Alberto Vertova

Received: 14 March 2021

Accepted: 8 April 2021

Published: 11 April 2021

Publisher's Note: MDPI stays neutral with regard to jurisdictional claims in published maps and institutional affiliations.

Copyright: (c) 2021 by the authors. Licensee MDPI, Basel, Switzerland. This article is an open access article distributed under the terms and conditions of the Creative Commons Attribution (CC BY) license (https:// creativecommons.org/licenses/by/ $4.0 /)$.

\begin{abstract}
Activated carbon is widely used as an electrode material in supercapacitors due to its superior electrochemical stability, excellent electrical conductivity, and environmental friendliness. In this study, the self-discharge mechanisms of activated carbon electrodes loaded with different contents of $\mathrm{Fe}$ impurities $\left(\mathrm{Fe}\right.$ and $\mathrm{Fe}_{3} \mathrm{O}_{4}$ ) were analyzed by multi-stage fitting to explore the tunability of self-discharge. It is was found that a small quantity of Fe impurities on carbon materials improves the self-discharge performance dominated by redox reaction, by adjusting the surface state and pore structure of carbon materials. As the content of Fe impurities increases, the voltage loss of activated carbon with the Fe impurity concentrations of $1.12 \mathrm{wt}$ \% (AF-1.12) decreases by 37.9\% of the original, which is attributable to the reduce of ohmic leakage and diffusion, and the increase in Faradic redox at the electrode/electrolyte interface. In summary, self-discharge performance of carbon-based supercapacitors can be adjusted via the surface state and pour structure, which provides insights for the future design of energy storage.
\end{abstract}

Keywords: supercapacitors; self-discharge; carbon; redox reactions

\section{Introduction}

Supercapacitors (SCs) are promising power storage devices due to their high-power density, ultra-long cycle life, reliable safety, and environmental friendliness [1-3]. In recent decades, the preparation process of novel SCs with high energy density and a large potential window has developed considerably. The supercritical drying process has been considered to be a promising method for the electrode materials of novel SCs. For example, an aerogel containing dispersed graphene as the porous electrode of novel SCs was fabricated using a supercritical $\mathrm{CO}_{2}$ process, which exhibited a high energy density of $79.2 \mathrm{Wh} \mathrm{kg}^{-1}$ at a power density of $0.23 \mathrm{KW} \mathrm{kg}^{-1}$ [4]. Furthermore, porous carbon microspheres as the electrode materials of SCs were prepared in a closed autoclave under high pressure, and exhibited a high capacitance of $633.2 \mathrm{~mA} \mathrm{~h} \mathrm{~g}^{-1}$ at $50 \mathrm{~mA} \mathrm{~g}^{-1}$ [5]. A carbon textile electrode was synthesized by vacuum impregnation and spray coating, resulting in excellent cycle performance at $1.5 \mathrm{~V} \mathrm{[6].} \mathrm{However,} \mathrm{the} \mathrm{application} \mathrm{of} \mathrm{novel} \mathrm{SCs} \mathrm{is} \mathrm{limited}$ by a rapid self-discharge (SDC) rate. SDC can be defined as a thermodynamic spontaneous process of energy decay, the appearance of which leads to low energy retention and large voltage loss $[7,8]$. The electrode material is an important factor that determines the SDC performance of SCs [9-11], due to its complex surface structure and chemistry state [2,12-14]. Activated carbon has attracted increasing attention in electrode materials due to its high specific surface area, adjustable pore structure, superior electrochemical performance, and low cost [15-17]. Thus, the SDC mechanisms of activated carbon have been further studied to inhibit voltage loss for electrochemical performance. 
To date, numerous studies have aimed to improve the SDC of carbon material by adjusting its surface structure and functional groups [14,18-20]. For instance, Wang et al. constructed nano-layers on the carbon surface, reducing the 50\% SDC rate of the original [13]. Davis and coworkers distinguished the effects between carbon oxidation and diffusion on SDC, and proposed that the redox reaction (17\% of SDC) could be the main factor of SDC for activated carbon [14]. Moreover, Yuan et al. proposed that removing the oxygen functional group of carbon by hydrogen thermal reduction can reduce the voltage loss of SDC, due to the increased stability of reaction at the electrode/electrolyte interface [1]. However, the self-discharge mechanism of Fe and its oxides on the carbon surface has not yet been identified in $\mathrm{KOH}$ electrolyte [2,12,21-24]. Therefore, in-depth study of the SDC mechanism caused by Fe impurities, in addition to clarifying the effects of their contents on SDC of carbon materials, are of significant importance for the development of advanced SC devices [25-27].

In this study, different contents of Fe impurities loaded on purified activated carbon (Fe@C composites) were synthesized by the vacuum impregnation process followed by annealing at $400^{\circ} \mathrm{C}$ for $2 \mathrm{~h}$ in an effort to establish a correlation between voltage loss during the SDC process, and contents of Fe and its oxides in SCs. The influences of Fe impurities on the structures and properties of the resulting samples were studied by scanning electron microscopy (SEM) and transmission electron microscopy (TEM). The crystal structures and valence states of Fe@C composites were investigated by X-ray diffraction (XRD), Raman spectroscopy, and X-ray photoelectron spectroscopy (XPS). The correlation between SDC performance and contents of Fe impurities was systematically investigated using MATLAB software. The results show that voltage loss during the SDC process could be effectively suppressed by introducing low-content Fe impurities in carbon electrodes.

\section{Experimental}

All reagents were purchased from Aladdin and used as received without further purification. Commercial activated carbon (AC, Hainan Xingguang Activated Carbon Co., Ltd., Wenchang, China) powder was washed by $10 \mathrm{vol} \% \mathrm{HCl}$ and sufficient deionized water to remove impurities, followed by drying at $80{ }^{\circ} \mathrm{C}$ for $12 \mathrm{~h}$. Fe@C was prepared by first dissolving $\mathrm{FeCl}_{3} \cdot 9 \mathrm{H}_{2} \mathrm{O}$ in distilled water to form a transparent solution. Next, $\mathrm{AC}(8 \mathrm{~g})$ was added into the above dispersion containing different concentrations of $\mathrm{FeCl}_{3}$ solution $(0.48,0.80,1.12$, and $1.6 \mathrm{wt} . \%)$ followed by vacuum impregnation and ultrasonic dispersion for $1 \mathrm{~h}$. The resulting homogeneously dispersed mixtures were filtered and dried at $120^{\circ} \mathrm{C}$ for $8 \mathrm{~h}$. Finally, the obtained powders were annealed at $400{ }^{\circ} \mathrm{C}$ for $2 \mathrm{~h}$ under argon flow to yield the samples AF-0.48, AF-0.8, AF-1.12, and AF-1.6.

The morphological microstructures of the samples were studied by scanning electron microscopy (SEM, Hitachi S-4800SEM, Hitachi, Tokyo, Japan), transmission electron microscopy (TEM, JEM-2100F, JEOL Ltd., Tokyo, Japan) and high-resolution transmission electron microscopy (HRTEM, JEM-2100F, JEOL Ltd., Tokyo, Japan). The crystal structures were obtained by X-ray diffraction (XRD, Bruker D8 advance, Bruker, Karlsruhe, Germany) with $\mathrm{Cu}-\mathrm{K} \alpha$ radiation in the scanning range from $10^{\circ}$ to $80^{\circ}$ and Raman spectroscopy (Thermo Fisher DXRxi, Waltham, MA, USA) under a laser excitation wavelength of $532 \mathrm{~nm}$. The energy dispersive spectroscopy (EDS, Hitachi, Tokyo, Japan) and X-ray photoelectron spectroscopy (XPS, ESCALAB 250xi, Thermo Fisher Scientific, Waltham, MA, USA) profiles were collected and used to analyze the surface chemical compositions of samples. The amounts of Fe in AC and Fe@C composites were collected by inductively coupled plasma mass spectrometry (ICP-MS, Agilent ICP-MS-7700, Agilent Technologies Inc., Santa Clara, CA, USA). The specific surface areas of the samples were collected using the BrunauerEmmett-Teller (BET) method on an AutoSorb iQ2 under liquid argon at $87 \mathrm{~K}$. The pore size distribution was calculated using the quenched-solid density functional theory (QSDFT) model based on the adsorption branch.

The Fe@C composite electrodes used for the fabrication of SCs were prepared by mixing active materials (load $\mathrm{Fe} / \mathrm{Fe}_{3} \mathrm{O}_{4}$ carbon powder, $85 \mathrm{wt} . \%$ ), conductive agent (Ketjen 
black, $10 \mathrm{wt.} \%$ ), and binder (polytetrafluoroethylene, $5 \mathrm{wt} . \%$ ) in ethyl alcohol to form a slurry. After mixing and shaking, the slurry was pressed on Ni foam $\left(1 \times 1 \mathrm{~cm}^{2}\right)$ and left to dry at $110^{\circ} \mathrm{C}$ under vacuum for $12 \mathrm{~h}$. The loading mass of the slurry on the electrodes was about $2 \mathrm{mg} \mathrm{cm}^{-2}$. Next, two Fe@C composite electrodes with the same mass were assembled into symmetrical SCs, in which $6 \mathrm{M} \mathrm{KOH}$ was employed as an electrolyte. The cycle performance and galvanostatic charge/discharge (GCD) profiles were tested using a Neware battery testing system at the charging current density of $1 \mathrm{~A} \mathrm{~g}^{-1}$ and $25^{\circ} \mathrm{C}$. The cyclic voltammetry (CV) curves were collected by Bio-logic VSPN-300 in the potential window from 0 to $1 \mathrm{~V}$ at the scan rate of $1 \mathrm{mV} \mathrm{s}^{-1}$. The electrochemical impedance spectroscopy (EIS) curves were collected in the frequency range from $1 \mathrm{mHz}$ to $100 \mathrm{kHz}$ at $5 \mathrm{mV}$ amplitude. The $24 \mathrm{~h}$ SDC curves were measured using a Neware battery testing system, and used to study the influence of iron impurity on the SDC process of carbonbased SCs.

\section{Results and Discussion}

The surface morphologies of Fe@C composites were investigated by SEM and the results are displayed in Figure 1a. The annealed Fe@C composites present irregular particles with porous structure. The porosity between the disordered particles and porous structure provides a favorable space for the penetration and diffusion of the electrolyte, which is useful for improving the capacitance of the SCs [28-30]. In addition, the Fe, C, and O elements are also uniformly distributed on the particle surface (Figure 1b). The crystal structures of Fe@C composites were further investigated by TEM and HRTEM measurements. As shown in Figure 1c,d, Fe and its oxides are uniformly anchored on the activated carbon surface, and the average size of particles in AF-1.12 is about $4.5 \mathrm{~nm}$ (inset picture of Figure 1c). Furthermore, the porous structure of activated carbon particles provides enough space for the multiphase changes of $\mathrm{Fe}_{3} \mathrm{O}_{4}$ to prevent significant volumetric expansion during the charge/discharge processes to maintain high cycling stability [31-34]. More direct evidence regarding the structure of Fe@C composites is illustrated in Figure 1d. For the AF-1.12 sample, the lattice distances are estimated to be $0.253 \mathrm{~nm}$ and $0.202 \mathrm{~nm}$ and attributed to (331) lattice planes of $\mathrm{Fe}_{3} \mathrm{O}_{4}$ and (110) lattice planes of Fe, respectively [35-39]. Thus, $\mathrm{Fe} / \mathrm{Fe}_{3} \mathrm{O}_{4}$ was successfully loaded on carbon using an impregnation process followed by annealing.

XRD and Raman spectroscopy were employed to further investigate the crystallinity and structure of Fe@C composites. The characteristic diffraction peaks at $2 \theta=35.42^{\circ}$ and $63^{\circ}$ correspond to the reflection planes of (311) and (440) in $\mathrm{Fe}_{3} \mathrm{O}_{4}$ with a face-centered cubic structure [36-38,40-42]. The diffraction peak at $2 \theta=44.73^{\circ}$ is assigned to the (110) lattice planes of body-centered-cubic Fe [36,40,43]. As Fe-doped content increases, the peak intensity of $\mathrm{Fe}_{3} \mathrm{O}_{4}$ and Fe increases, implying enhanced Fe impurities on the Fe@C composite surface. In addition, the Fe contents of Fe@C composites were collected by ICP-MS, and are larger than that of AC $\left(425 \mathrm{mg} \mathrm{kg}^{-1}\right)$ (Table S1). As the Fe-doping content increases, the Fe contents of AF-0.48, AF-0.8, AF-1.12, and AF-1.6 increase to 3260.2, 4625.3, 6952.0, and $9911.5 \mathrm{mg} \mathrm{kg}^{-1}$, respectively. To further study the effect of Fe-doping on surface structure of active carbon, Raman spectroscopy was carried out and the results are shown in Figure 2b. All samples exhibit two typical carbon peaks at $1360 \mathrm{~cm}^{-1}$ (Dband) and $1580 \mathrm{~cm}^{-1}$ (G-band) [42,44,45], ascribed to the amorphous and graphitic carbon structure $[46,47]$, respectively. The intensity ratio of the D-band and G-band $\left(\mathrm{I}_{\mathrm{D}} / \mathrm{I}_{\mathrm{G}}\right)$ reflects the degree of surface disorder of carbon materials. The calculated $\mathrm{I}_{\mathrm{D}} / \mathrm{I}_{\mathrm{G}}$ values of the samples AC, AF-0.48, AF-0.8, AF-1.12, and AF-1.6 are 1.05, 1.06, 1.07, 1.08, and 1.10, respectively. This result indicates that the degree of surface disorder is more pronounced, which is attributed to the increase in Fe impurities [37,48,49]. In addition to SEM and TEM analyses, the XRD patterns and Raman spectra also confirm the formation of $\mathrm{Fe}_{3} \mathrm{O}_{4}$ and $\mathrm{Fe}$ phases in activated carbon through the impregnation process. 

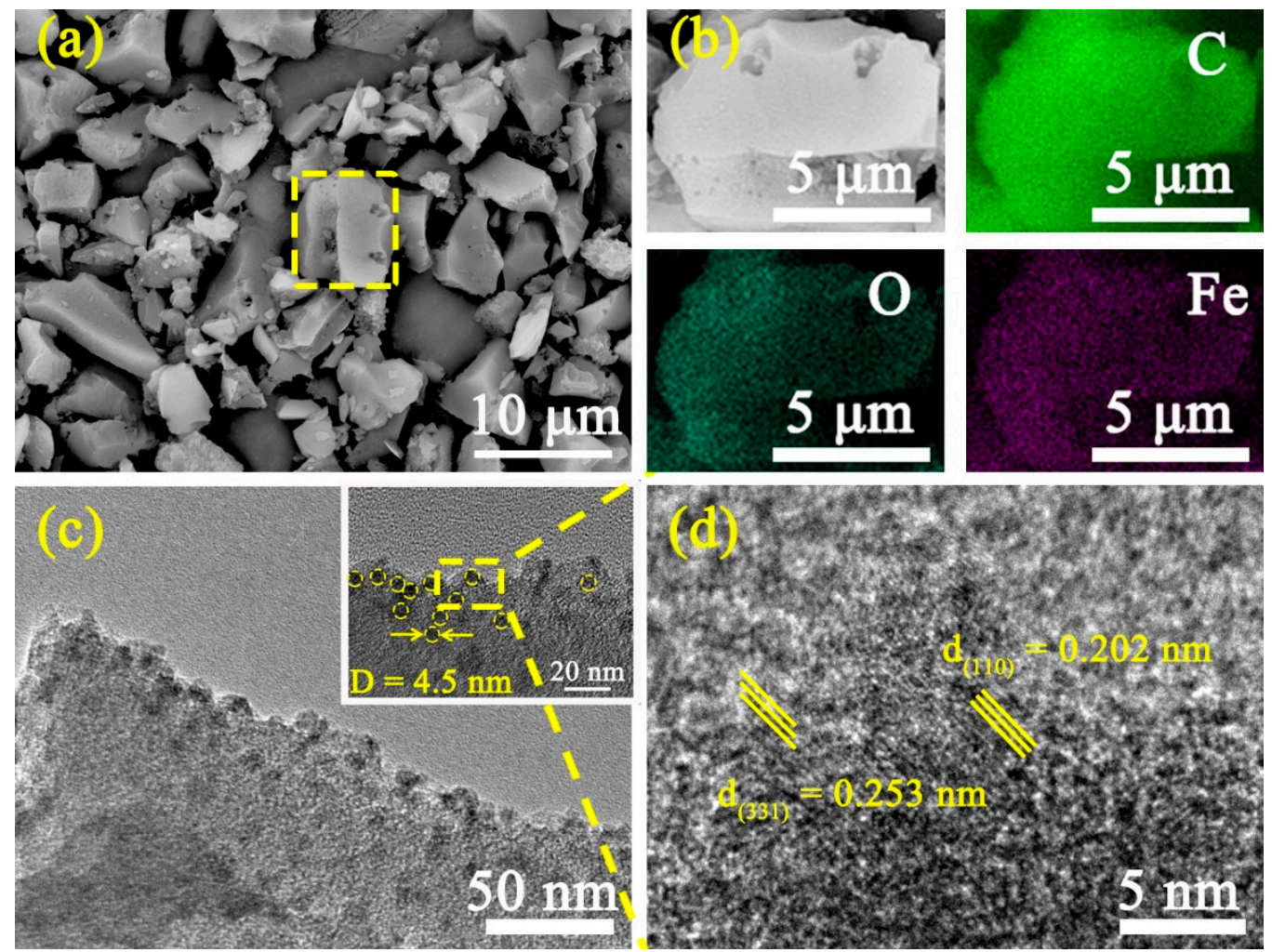

Figure 1. (a) SEM images; (b) EDS results; (c) TEM, and (d) HRTEM images of AF-1.12 sample.
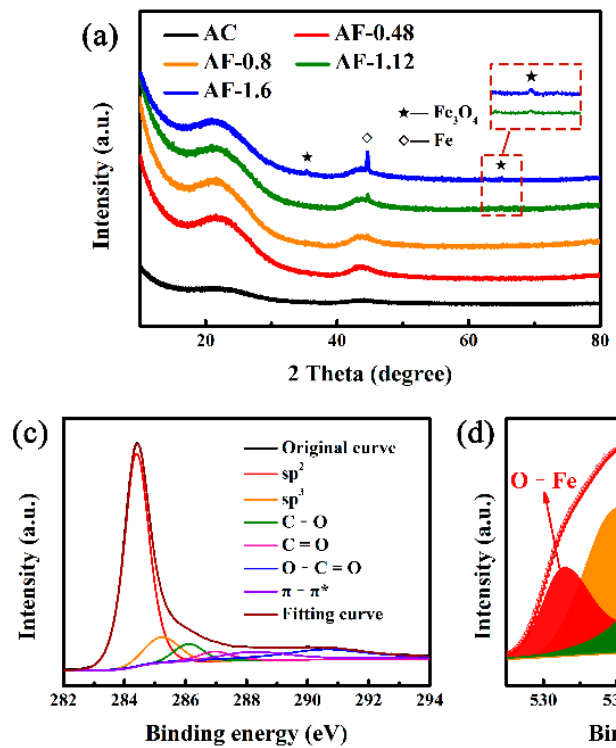

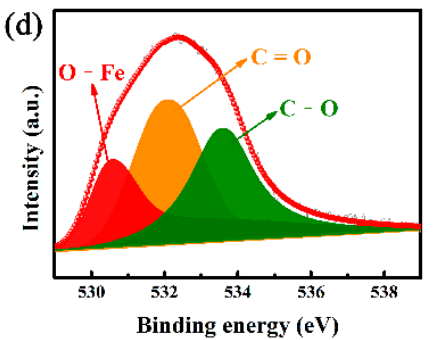

Figure 2. (a) XRD patterns and (b) Raman spectra of AC and Fe@C composites; high resolution XPS survey of AF-1.12: (c) C 1s, (d) O 1s, and (e) Fe 2p.

To determine the valence states of Fe and its oxides, XPS measurements were carried out. As shown in Figure S1, the XPS survey scan unambiguously indicates the presence of $\mathrm{C}, \mathrm{O}$, and $\mathrm{Fe}$ elements. The increase in $\mathrm{Fe} / \mathrm{Fe}_{3} \mathrm{O}_{4}$ content leads to a gradual enhancement in the peak intensity of Fe $2 \mathrm{p}$ corresponding to the Fe@C composite when compared to that of AC. The high-resolution spectra of C 1 s are divided into six peaks at of 284.7, 285.4, 286.2, 287.4, 288.7, and $290 \mathrm{eV}$, corresponding to $\mathrm{sp}^{2}$ (graphitic carbon, C-C peak), $\mathrm{sp}^{3}$ hybridized carbon (defects peak), $\mathrm{C}-\mathrm{O}, \mathrm{C}=\mathrm{O}, \mathrm{O}-\mathrm{C}=\mathrm{O}$, and $\pi-\pi^{*}$, respectively (Figure $2 \mathrm{c}$ ) $[24,43,50,51]$. As shown in Figure S2 and Table S2, the increase in Fe-doping content leads to the gradual 
transformation from $\mathrm{sp}^{2}-\mathrm{C}$ to $\mathrm{sp}^{3}-\mathrm{C}$, indicating the decrease in graphitization degree [51]. This result is consistent with the XRD and Raman results. In Figure $2 \mathrm{~d}$, the $\mathrm{O} 1 \mathrm{~s}$ could be deconvoluted into three peaks at 530.2, 531.8, and $533.2 \mathrm{eV}$, corresponding to $\mathrm{O}-\mathrm{Fe}_{\mathrm{fe}} \mathrm{Fe}_{3} \mathrm{O}_{4}$, $\mathrm{O}=\mathrm{C}$, and $\mathrm{O}-\mathrm{C}$, respectively $[40,41,43,50]$. In the Fe $2 \mathrm{p}$ spectrum of AF-1.12 (Figure 2e), five peaks at 710.8, 712.7, 719.0, 724.5, and $725.2 \mathrm{eV}$ are observed. These are associated with, respectively, $\mathrm{Fe} 2 \mathrm{p}_{3 / 2}$, shake-up satellite and $\mathrm{Fe} 2 \mathrm{p}_{1 / 2}$ of $\mathrm{Fe}^{2+}$ and $\mathrm{Fe}^{3+}$, indicating the presence of $\mathrm{Fe}_{3} \mathrm{O}_{4}[28,36,37,50]$. As a result, a unique complex system consisting of $\mathrm{Fe} @ \mathrm{C}$ with different doping concentrations was obtained.

The surface areas and pore size distributions of $\mathrm{AC}$ and Fe@C composites were investigated by Ar adsorption isotherms at $87 \mathrm{~K}$. As shown in Figure $3 \mathrm{a}$, all samples display a combined I/IV isotherm $[15,35,37,42,49,52,53]$. Specifically, the rapid increase in isotherms in the low-pressure region is a typical characteristic of a micro-porous structure [54]. The adsorption/desorption isotherms in the high-pressure region exhibit a non-obvious platform and the type $\mathrm{H} 4$ hysteresis loops, indicating the presence of meso-pores [35]. The effects of $\mathrm{Fe} / \mathrm{Fe}_{3} \mathrm{O}_{4}$ on the surface pore size distributions were further studied using the QSDFT method. As shown in Figure 3b, all samples have micro-pores (pore size $<2 \mathrm{~nm}$ ) and meso-pores (pore size between 2 and $50 \mathrm{~nm}$ ), and the volume of the former is higher than that of latter. In Table S3, as Fe-doping content rises, the specific area increases from $1503.9 \mathrm{~m}^{2} \mathrm{~g}^{-1}$ (AC) to $1676.81 \mathrm{~m}^{2} \mathrm{~g}^{-1}$ (AF-1.12) and then decreases to $1586.46 \mathrm{~m}^{2} \mathrm{~g}^{-1}$ (AF-1.6). AF-1.2 exhibits the highest specific area of $1671.81 \mathrm{~m}^{2} \mathrm{~g}^{-1}, 11.2 \%$ higher than that of AC. The larger surface area can be attributed to the increase in the microporous volume by the etching effect of $\mathrm{Fe}_{3} \mathrm{O}_{4}$ during the heat treatment process [55,56] (Figure 3b). The specific area of AF-1.6 is $1586.46 \mathrm{~m}^{2} \mathrm{~g}^{-1}$, which is smaller than that of AC-1.2. The reduction of specific surface area can be attributed to the reduction of the microporous volume, which is due to the destruction of the microporous structure on the carbon surface caused by the massive growth of $\mathrm{Fe} / \mathrm{Fe}_{3} \mathrm{O}_{4}$ [57].
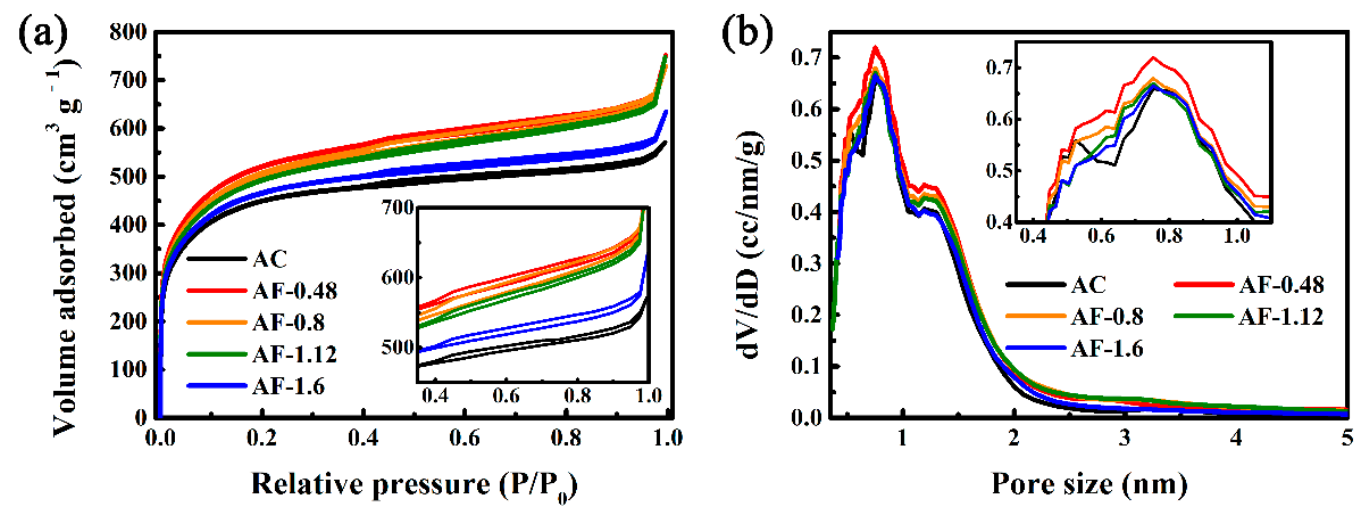

Figure 3. Ar adsorption/desorption isotherms (a) and corresponding pore size distributions (b) of AC and Fe@C composites.

The capacitive performances of AC and Fe@C composites were investigated in $6 \mathrm{M}$ $\mathrm{KOH}$ for over 10,000 cycles. As shown in Figure 4a, as Fe-doping content rises, the specific capacitance increases from $146.7 \mathrm{~F} \mathrm{~g}^{-1}$ (AC) to $186.2 \mathrm{~F} \mathrm{~g}^{-1}$ (AF-1.12) and then decreases to 173.2 $\mathrm{F} \mathrm{g}^{-1}$ (AF-1.6). AF-1.2 exhibits the highest specific capacitance of $186.2 \mathrm{~F} \mathrm{~g}^{-1}, 26.9 \%$ higher than that of AC. The enhanced electrochemical performance can be attributed to the introduction of $\mathrm{Fe} / \mathrm{Fe}_{3} \mathrm{O}_{4}$, which increases the pseudo-capacitance by redox reactions in the interface between the electrode and the electrolyte. The specific capacitance of AF-1.6 is $173.2 \mathrm{~F} \mathrm{~g}^{-1}$, which is smaller than that of AC-1.2. The reduction of specific capacitance can be attributed to the reduction of the double-layer capacitance caused by the destruction of the microporous structure and the reduction of specific surface areas. After 10,000 cycles, the specific capacitance of AF- 1.12 remained at $178 \mathrm{~F} \mathrm{~g}^{-1}$, indicating excellent cycle stability (Figure 4a). The degradation in long-cycle performance is caused by the instability of increased pseudo-capacitance by Fe and its oxides. The GCD curves of Fe@C 
composites appear nonlinear and asymmetrical, suggesting a strong pseudo-capacitive behavior (Figure 4b) [44,51,57].

(a)

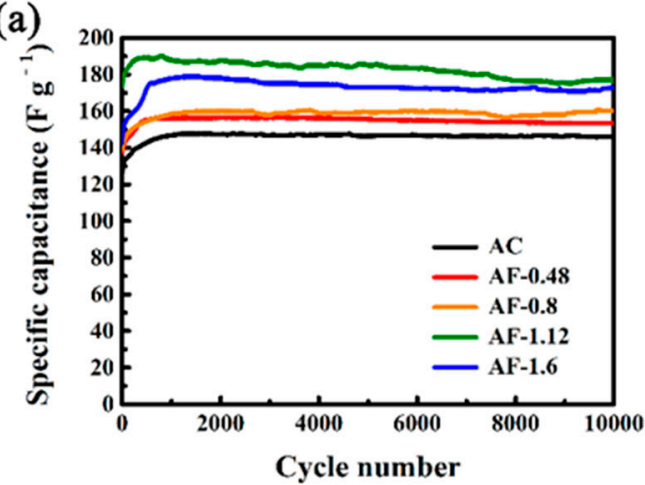

(c)

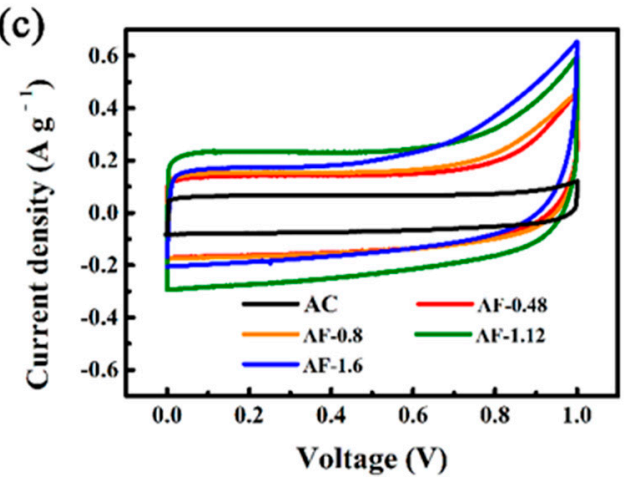

(b)

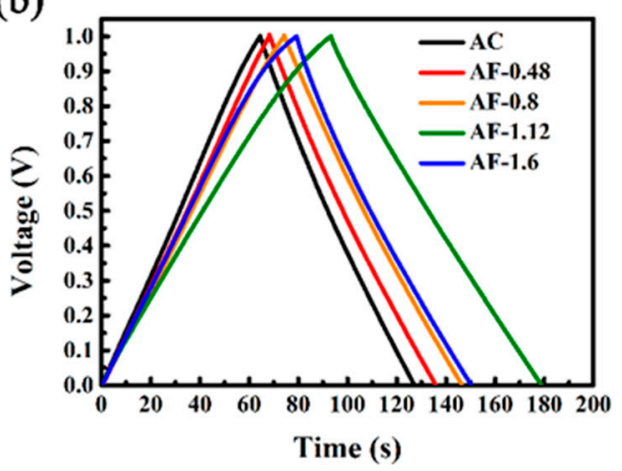

(d)

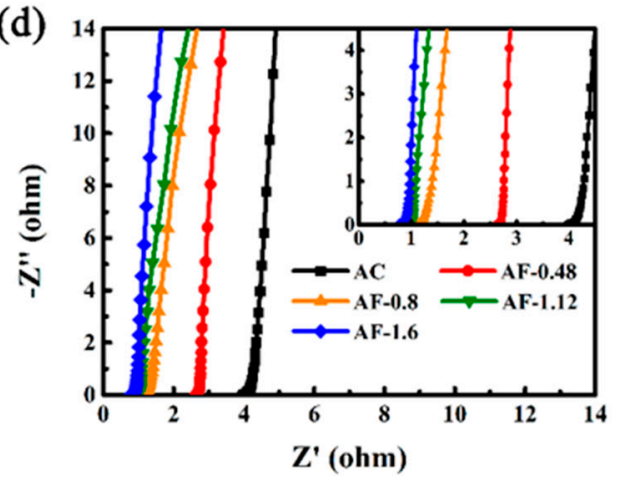

Figure 4. Cycle performances (a); galvanostatic charge/discharge (GCD) curves (b) at $1 \mathrm{~A} \mathrm{~g}^{-1}$; $\mathrm{CV}$ curves (c) at $1 \mathrm{mV} / \mathrm{s}$, and Nyquist plots (d) of AC and Fe@C composite supercapacitor (SC) electrodes.

To gain further insights into the effects of $\mathrm{Fe}$ and $\mathrm{Fe}_{3} \mathrm{O}_{4}$ on the electrochemical performances, CV and EIS curves were recorded and the results are gathered in Figure 4c,d. The CV curves of Fe@C composites display asymmetrical pseudo-capacitance behavior (Figure 4c), corroborating the GCD curves. The asymmetrical CV curve of AF-1.12 suggests the presence of pseudo-capacitance during the charge and discharge processes [41,58]. In Figure $4 \mathrm{~d}$, the $\mathrm{X}$-intercept of the semicircles in the Nyquist plots in the high-frequency region is related to the ohmic resistance of the $S C s\left(R_{o h m}\right)$, which represents the total resistance produced by the electrolyte, current collectors, and electrodes [28,29]. Among all of the samples, the AC exhibits the highest $R_{\text {ohm }}$ of $3.88 \Omega$, which can be attributed to the low charge-transfer rate caused by its uneven surface and the intricate conductive network. With increases in the loading amounts of $\mathrm{Fe}$ and $\mathrm{Fe}_{3} \mathrm{O}_{4}$, the $\mathrm{R}_{\mathrm{ohm}}$ values decrease to $2.57,1.08,0.94$, and $0.71 \Omega$ for AF-0.48, AF-0.8, AF-1.12, and AF-1.6, respectively. Such a significant decrease occurred because the Fe element contributed to structural rearrangement and more active sites on the carbon surface, which accelerates charge separation and transport [59-62]. In the low-frequency region, the impedance plots of all samples become oblique lines, showing pure capacitance.

The main form of self-discharge of charged SCs relies on voltage attenuation [12,63]. The devices undergo two and a half cycles of charge/discharge (at $1 \mathrm{~A} \mathrm{~g}^{-1}$ ) and then hold at $1 \mathrm{~V}$ for $2 \mathrm{~h}$ to reduce the influence of uneven charges on the electrode surface. As shown in Figure $5 \mathrm{a}$, the potential of AC drops to $0.27 \mathrm{~V}$ after $24 \mathrm{~h}$, equivalent to $73 \%$ voltage loss in the SCs. By comparison, AF-0.48 takes the same time to drop its potential to $0.46 \mathrm{~V}$, equivalent to only $54 \%$ voltage loss. The increase in $\mathrm{Fe}$ and $\mathrm{Fe}_{3} \mathrm{O}_{4}$ contents leads to the gradual decline in the voltage loss of SDC. Compared with the potential decay of AC, that of AF-1.12 is reduced by $39.7 \%$ ( $0.56 \mathrm{~V}$, equivalent to only $44 \%$ voltage loss) after $24 \mathrm{~h}$. According to the mathematical models proposed by Conway et al., the potential 
decay is caused by three mechanisms of SCs, consisting of ohmic leakage, Faraday reaction, and diffusion (Figure 6) [12,14]. The potential decay is caused by the internal resistances between the positive and negative electrodes, which can be described by the ohmic leakage mechanism in Figure $6 b(\mathrm{~V} \sim \exp (\mathrm{t}))[63,64]$. As shown in Figure $6 c$, the potential decay is attributed to the departure of ions from the electric double layer during the SDC process, which is the diffusion mechanism $\left(\mathrm{V} \sim \mathrm{t}^{1 / 2}\right)[12,24]$. The potential decay is related to the redox reactions of impurities on the electrode surface, which can be described by the Faradic redox mechanism $(\mathrm{V} \sim \ln (\mathrm{t})$ ) (Figure $6 \mathrm{~d}$ ) [14,24,62]. Combining the potential decay caused by all three mechanisms, Equation (1) can be obtained $[63,65]$.

$$
\mathrm{U}=\mathrm{U}_{0}-\operatorname{Aexp}(\mathrm{t})-\mathrm{Bt}^{\frac{1}{2}}-\mathrm{Dln}(\mathrm{t})-\mathrm{e}
$$

where $U$ and $U_{0}$ represent the final potential and initial potential $(1.0 \mathrm{~V})$ of the charged SC. $t$ is the discharge time $(24 \mathrm{~h})$. A and B correspond to the time constant and diffusion parameter of the SDC process, respectively. e and D denote the constants in the Faradaic process, related to the current density.
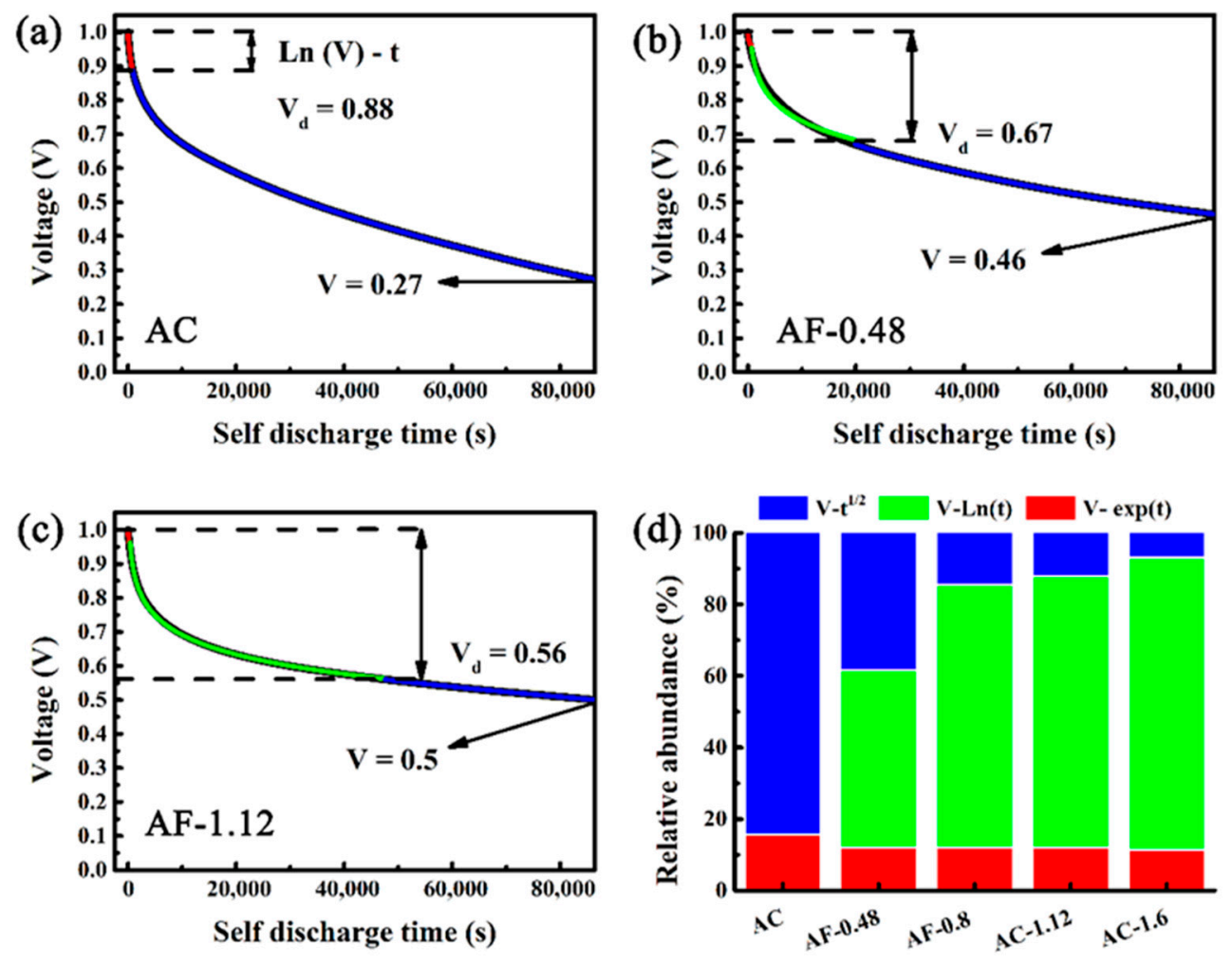

Figure 5. Simulated self-discharge (SDC) of AC and Fe@C composite electrodes by multiple processes: (a) AC electrode, (b) AF-0.48 electrode, and (c) AF-1.12 electrode. The control time of different selfdischarging processes $(\mathbf{d})$.

The effects of $\mathrm{Fe} / \mathrm{Fe}_{3} \mathrm{O}_{4}$ on SDC were further studied by establishing the SDC mechanisms by multi-stage fitting in MATLAB. In Figure $5 a-c$, the SDC process consists of three parts. The ohmic leakage mechanism represents the first part (red curve), the Faradic redox mechanism displays the second part (green curve), and the diffusion mechanism shows the last part (blue curve). The fitting curves match well with the test results (black curve), confirming the complex nature of the SDC process from the ohmic leakage mechanism to the diffusion mechanism. $V_{d}$ represents the occurrence of the voltage of the diffusion mechanism. As shown in Figure 5d, as the content of Fe-doping increases, the decrease in $\mathrm{R}_{\mathrm{ohm}}$ leads to a decline in SDC controlled by the ohmic leakage mechanism. In addition, with an increase in Fe-doping content, the reduction of micro-pores leads to a decrease in $\mathrm{V}_{\mathrm{d}}$, indicating the weakening of SDC caused by diffusion mechanism. By contrast, the 
redox of $\mathrm{Fe}$ and $\mathrm{Fe}_{3} \mathrm{O}_{4}$ enhances the SDC controlled by the Faradic redox mechanism, corroborating the $\mathrm{CV}$ and GCD data. However, SDC can increase again at high doping levels, which is due to the destruction of the surface structure by volume expansion of $\mathrm{Fe}_{3} \mathrm{O}_{4}$ (Figure S3). As a result, the redox reactions can change the voltage loss of SDC at low contents of Fe and its oxides.

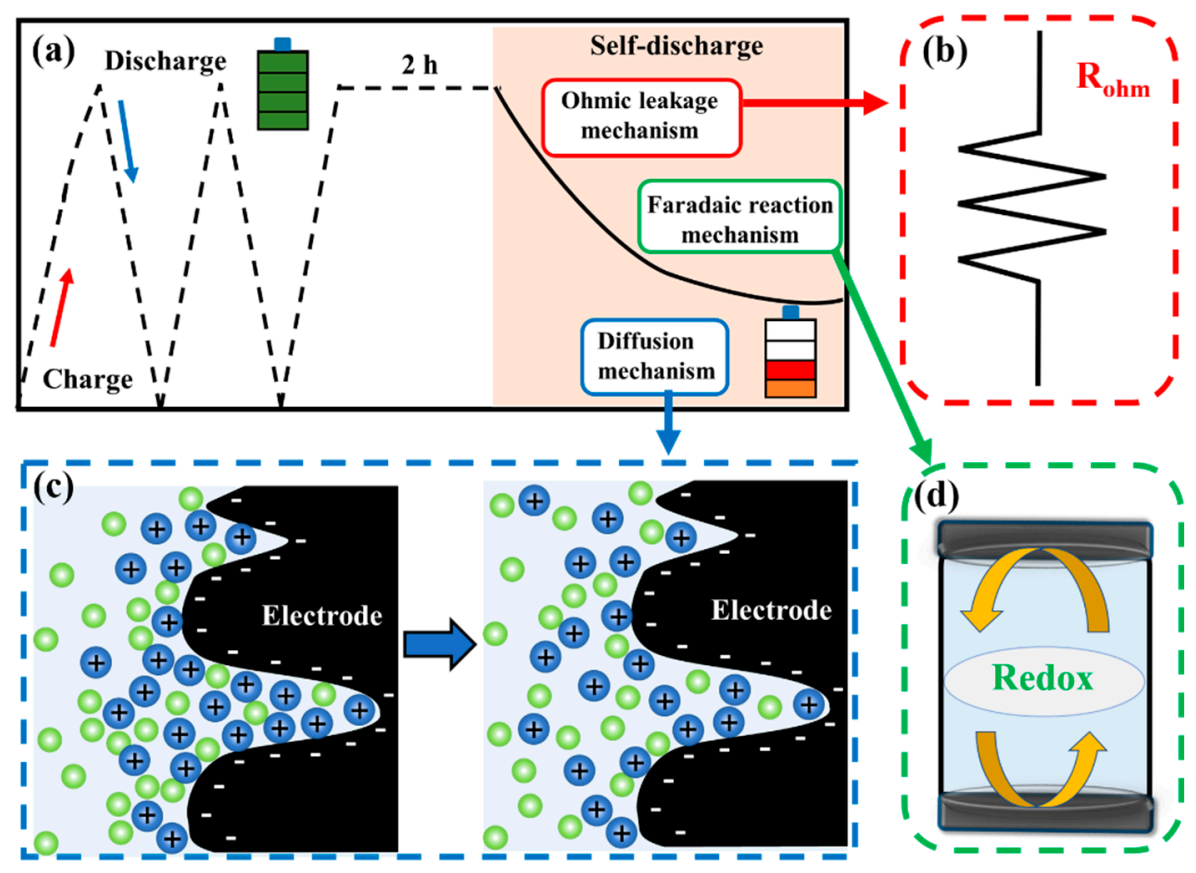

Figure 6. (a) Illustration of the experiment; The mechanisms of SDC in SCs: (b) ohmic leakage mechanism; (c) diffusion mechanism; and (d) Faraday reaction mechanism.

\section{Conclusions}

Different contents of $\mathrm{Fe} / \mathrm{Fe}_{3} \mathrm{O}_{4}$ were successfully introduced into activated carbon by vacuum impregnation followed by annealing. The influence of Fe-doping content on SDC of carbon materials was systematically investigated. The proportion of ohmic leakage, redox, and diffusion mechanism of SDC processes was analyzed using MATLAB. The introduction of $\mathrm{Fe} / \mathrm{Fe}_{3} \mathrm{O}_{4}$ at low contents into activated carbon (AF-1.12) leads to a drastic reduction in SDC, of more than $39.7 \%$, which was attributed to the decreased decay of potential caused by the diffusion mechanism and ohmic leakage mechanism in charged SCs. AF-1.12 showed the highest specific capacitance $\left(186.2 \mathrm{~F} \mathrm{~g}^{-1}\right)$ and excellent cycle stability, thus showing promise for the improvement of small power storage devices.

Supplementary Materials: The following are available online at https:/ / www.mdpi.com/article/10 $.3390 /$ ma14081908/s1, Figure S1: X-ray photoelectron wide scan spectra (a) and Fe 2p spectra (b) of AC and the Fe@C composites, Figure S2: C1s spectra of AC (a); AF-0.48 (b); AF-0.8 (c) and AF-1.6 (d), Figure S3: Self-discharge curves of AF-0.8 and AF-1.6, Table S1 The amounts of Fe in AC and Fe@C composites were investigated using ICP-MS, Table S2: Atomic percentage concentrations (\%) of the peak area at $\mathrm{C}, \mathrm{O}$, and Fe binding energy in the XPS spectra (a) and percentage (\%) of the peak area at sp2 and sp3 binding energy in the XPS spectra of C1s, Table S3: Specific surface areas of AC and $\mathrm{Fe} / \mathrm{Fe}_{3} \mathrm{O}_{4}$ composites were investigated using Ar adsorption isotherms at $87 \mathrm{~K}$.

Author Contributions: Conceptualization, methodology and formal analysis, Y.D.; investigation, data curation, and writing, Y.D. Y.M. and Y.C.; All authors have read and agreed to the published version of the manuscript. 
Funding: Key Research and Development Project of Hainan Province (ZDYF2020028), National Natural Science Foundation of China (52062012), the Innovation Team of Universities of Guangdong Province (2020KCXTD011), the Engineering Research Center of Universities of Guangdong Prov-ince (2019GCZX002), the Guangdong Key Laboratory for Hydrogen Energy Technologies (2018B030322005).

\section{Institutional Review Board Statement: Not applicable.}

Informed Consent Statement: Not applicable.

Data Availability Statement: All data is contained within the article.

Conflicts of Interest: The authors declare no known competing financial interests or personal relationships that could influence the work reported in this paper.

\section{References}

1. Yuan, S.; Huang, X.; Wang, H.; Xie, L.; Cheng, J.; Kong, Q.; Sun, G.; Chen, C.-M. Structure evolution of oxygen removal from porous carbon for optimizing supercapacitor performance. J. Energy Chem. 2020, 51, 396-404. [CrossRef]

2. Wang, B.; Wang, C.; Hu, Q.; Zhang, L.; Wang, Z. Modeling the dynamic self-discharge effects of supercapacitors using a con-trolled current source based ladder equivalent circuit. J. Energy Storage 2020, 30, 101473-101490. [CrossRef]

3. Zhang, D.; Guo, X.; Tong, X.; Chen, Y.; Duan, M.; Shi, J.; Jiang, C.; Hu, L.; Kong, Q.; Zhang, J. High-performance battery-type supercapacitor based on porous biocarbon and biocarbon supported Ni-Co layered double hydroxide. J. Alloys Compd. 2020, 837, 155529. [CrossRef]

4. Sarno, M.; Baldino, L.; Scudieri, C.; Cardea, S.; Reverchon, E. A one-step SC-CO2 assisted technique to produce compact PVDF-HFP MoS2 supercapacitor device. J. Phys. Chem. Solids 2020, 136, 109132. [CrossRef]

5. Qian, Y.; Jiang, S.; Li, Y.; Yi, Z.; Zhou, J.; Tian, J.; Lin, N.; Qian, Y. Understanding mesopore volume-enhanced extra-capacity: Optimizing mesoporous carbon for high-rate and long-life potassium-storage. Energy Storage Mater. 2020, 29, 341-349. [CrossRef]

6. Yong, S.; Owen, J.; Beeby, S. Solid-State Supercapacitor Fabricated in a Single Woven Textile Layer for E-Textiles Applications. Adv. Eng. Mater. 2018, 20, 1700860. [CrossRef]

7. Lewandowski, A.; Jakobczyk, P.; Galinski, M.; Biegun, M. Self-discharge of electrochemical double layer capacitors. Phys. Chem. Chem. Phys. 2013, 15, 8692-8699. [CrossRef]

8. Yang, H.; Zhang, Y. Self-discharge analysis and characterization of supercapacitors for environmentally powered wireless sensor network applications. J. Power Sources 2011, 196, 8866-8873. [CrossRef]

9. Yang, X.; Li, Y.; Zhang, P.; Sun, L.; Ren, X.; Mi, H. Hierarchical hollow carbon spheres: Novel synthesis strategy, pore structure engineering and application for micro-supercapacitor. Carbon 2020, 157, 70-79. [CrossRef]

10. Wu, C.-W.; Unnikrishnan, B.; Chen, I.-W.P.; Harroun, S.G.; Chang, H.-T.; Huang, C.-C. Excellent oxidation resistive MXene aqueous ink for micro-supercapacitor application. Energy Storage Mater. 2020, 25, 563-571. [CrossRef]

11. Pan, Z.; Yang, J.; Li, L.; Gao, X.; Kang, L.; Zhang, Y.; Zhang, Q.; Kou, Z.; Zhang, T.; Wei, L.; et al. All-in-one stretchable coaxial-fiber strain sensor integrated with high-performing supercapacitor. Energy Storage Mater. 2020, 25, 124-130. [CrossRef]

12. Wang, Z.; Chu, X.; Xu, Z.; Su, H.; Yan, C.; Liu, F.; Gu, B.; Huang, H.; Xiong, D.; Zhang, H.; et al. Extremely low self-discharge solid-state supercapacitors via the confinement effect of ion transfer. J. Mater. Chem. A 2019, 7, 8633-8640. [CrossRef]

13. Wang, Y.; Shan, X.; Wang, D.; Cheng, H.; Li, F. Mitigating self-discharge of carbon based electrochemical capacitors by modi-fying their electric double layer to maximize energy efficiency. J. Energy Chem. 2019, 38, 214-218. [CrossRef]

14. Davis, M.; Andreas, H. Identification and isolation of carbon oxidation and charge redistribution as self-discharge mechanisms in reduced graphene oxide electrochemical capacitor electrodes. Carbon 2018, 139, 299-308. [CrossRef]

15. Zhu, Z.; Yin, H.; Wang, Y.; Chuang, C.; Xing, L.; Dong, M.; Lu, Y.; Casillas-Garcia, G.; Zheng, Y.; Chen, S.; et al. Coexisting Single-Atomic Fe and Ni Sites on Hierarchically Ordered Porous Carbon as a Highly Efficient ORR Electrocatalyst. Adv. Mater. 2020, 32, 2004670. [CrossRef] [PubMed]

16. Zhang, X.; Liao, H.; Liu, X.; Shang, R.; Zhou, Y.; Zhou, Y. Facile synthesis of $\mathrm{Fe}_{2} \mathrm{O}_{3}$ nanospheres anchored on oxidized graphitic carbon nitride as a high performance electrode material for supercapacitors. Int. J. Electrochem. Sci. 2020, 15, 2133-2144. [CrossRef]

17. Li, J.; Wang, Y.; Xu, W.; Wang, Y.; Zhang, B.; Luo, S.; Zhou, X.; Zhang, C.; Gu, X.; Hu, C. Porous Fe $\mathrm{O}_{3}$ nanospheres anchored on activated carbon cloth for high-performance symmetric supercapacitors. Nano Energy 2019, 57, 379-387. [CrossRef]

18. Oickle, A.M.; Tom, J.; Andreas, H.A. Carbon oxidation and its influence on self-discharge in aqueous electrochemical capac-itors. Carbon 2016, 110, 232-242. [CrossRef]

19. Ike, I.S.; Sigalas, I.; Iyuke, S. Understanding performance limitation and suppression of leakage current or self-discharge in electrochemical capacitors: A review. Phys. Chem. Chem. Phys. 2016, 18, 661-680. [CrossRef]

20. Andreas, H.A. Self-Discharge in Electrochemical Capacitors: A Perspective Article. J. Electrochem. Soc. 2015, 162, A5047-A5053. [CrossRef]

21. Andreas, H.A.; Black, J.M.; Oickle, A.A. Self-discharge in Manganese Oxide Electrochemical Capacitor Electrodes in Aqueous Electrolytes with Comparisons to Faradaic and Charge Redistribution Models. Electrochim. Acta 2014, 140, 116-124. [CrossRef] 
22. Zhang, Q.; Rong, J.; Wei, B. A divided potential driving self-discharge process for single walled carbon nanotube based su-percapacitors. RSC Adv. 2011, 1, 989-994. [CrossRef]

23. Anantharaj, S.; Kundu, S.; Noda, S. The Fe Effect: A review unveiling the critical roles of Fe in enhancing OER activity of Ni and Co based catalysts. Nano Energy 2021, 80, 105514. [CrossRef]

24. Zhang, Q.; Cai, C.; Qin, J.; Wei, B. Tunable self-discharge process of carbon nanotube based supercapacitors. Nano Energy 2014, 4, 14-22. [CrossRef]

25. Andreas, H.A.; Lussier, K.; Oickle, A.M. Effect of Fe contamination on rate of self-discharge in carbon-based aqueous electrochemical capacitors. J. Power Sources 2009, 187, 275-283. [CrossRef]

26. Hess, L.; Fulik, N.; Röhner, J.; Zhang, E.; Kaskel, S.; Brunner, E.; Balducci, A. The role of diffusion processes in the self-discharge of electrochemical capacitors. Energy Storage Mater. 2021, 37, 501-508. [CrossRef]

27. Chung, J.; Park, H.; Jung, C. Electropolymerizable isocyanate-based electrolytic additive to mitigate diffusion-controlled selfdischarge for highly stable and capacitive activated carbon supercapacitors. Electrochim. Acta 2021, 369, 137698. [CrossRef]

28. Wang, S.; Liu, X.; Duan, H.; Deng, Y.; Chen, G. Fe $\mathrm{F}_{3} \mathrm{C} / \mathrm{Fe}$ nanoparticles embedded in N-doped porous carbon nanosheets and graphene: A thin functional interlayer for PP separator to boost performance of Li-S batteries. Chem. Eng. J. 2021, 415, 129001. [CrossRef]

29. Liao, B.; Li, H.; Xu, M.; Xing, L.; Liao, Y.; Ren, X.; Fan, W.; Yu, L.; Xu, K.; Li, W. Designing Low Impedance Interface Films Simultaneously on Anode and Cathode for High Energy Batteries. Adv. Energy Mater. 2018, 8, 1800802. [CrossRef]

30. Luo, X.; Chen, S.; Hu, T.; Chen, Y.; Li, F. Renewable biomass-derived carbons for electrochemical capacitor applications. Sustain. Mater. 2021. [CrossRef]

31. Deng, Y.; Zheng, Y.; Zhang, D.; Han, C.; Cheng, A.; Shen, J.; Zeng, G.; Zhang, H. A novel and facile to synthesize three dimensional honeycomb like nano- $\mathrm{Fe}_{3} \mathrm{O}_{4} @ \mathrm{C}$ composite: Electromagnetic wave absorption with wide bandwidth. Carbon 2020, 169, 118-128. [CrossRef]

32. Li, Z.; Lin, H.; Ding, S.; Ling, H.; Wang, T.; Miao, Z.; Zhang, M.; Meng, A.; Li, Q. Synthesis and enhanced electromagnetic wave absorption performances of $\mathrm{Fe}_{3} \mathrm{O}_{4} @ \mathrm{C}$ decorated walnut shell-derived porous carbon. Carbon 2020, 167, 148-159. [CrossRef]

33. Meng, X.; Liu, Y.; Han, G.; Yang, W.; Yu, Y. Three dimensional $\left(\mathrm{Fe}_{3} \mathrm{O}_{4} / \mathrm{ZnO}\right) @ \mathrm{C}$ Double core@shell porous nanocomposites with enhanced broadband microwave absorption. Carbon 2020, 162, 356-364. [CrossRef]

34. Li, R.; Wang, Y.; Zhou, C.; Wang, C.; Ba, X.; Li, Y.; Huang, X.; Liu, J. Carbon-stabilized high-capacity ferroferric oxide nanorod array for flexible solid-state alkaline battery-supercapacitor hybrid device with high environmental suitability. Adv. Funct. Mater. 2015, 25, 5384-5394. [CrossRef]

35. Peng, Z.; Hu, Y.; Wang, J.; Liu, S.; Li, C.; Jiang, Q.; Lu, J.; Zeng, X.; Peng, P.; Li, F. Fullerene-based in situ doping of N and Fe into a 3D cross-like hierarchical carbon composite for high-performance supercapacitors. Adv. Energy Mater. 2019, 9, 1802928-1802938. [CrossRef]

36. Venkateswarlu, S.; Lee, D.; Yoon, M. Bioinspired 2D-Carbon flakes and $\mathrm{Fe}_{3} \mathrm{O}_{4}$ nanoparticles composite for arsenite removal. ACS Appl. Mater. Interfaces 2016, 8, 23876-23885. [CrossRef]

37. Zhao, C.; Shao, X.; Zhang, Y.X.; Qian, X. Fe $\mathrm{O}_{3} / \mathrm{RGO} / \mathrm{Fe}_{3} \mathrm{O}_{4}$ composite in situ grown on Fe foil for high performance supercapacitors. ACS Appl. Mater. Interfaces 2016, 8, 30133-30142. [CrossRef]

38. Ren, Y.-L.; Wu, H.-Y.; Lu, M.-M.; Chen, Y.-J.; Zhu, C.-L.; Gao, P.; Cao, M.-S.; Li, C.-Y.; Ouyang, Q.-Y. Quaternary Nanocomposites Consisting of Graphene, $\mathrm{Fe}_{3} \mathrm{O}_{4} @ \mathrm{Fe}$ Core@Shell, and ZnO Nanoparticles: Synthesis and Excellent Electromagnetic Absorption Properties. ACS Appl. Mater. Interfaces 2012, 4, 6436-6442. [CrossRef]

39. Niu, Y.; Li, X.; Dong, W.; Zhang, C.; Zhao, K.; Wang, F.; Wang, H. Synthesis of N-doped carbon with embedded Fe/Fe3C particles for microwave absorption. J. Mater. Sci. 2020, 55, 11970-11983. [CrossRef]

40. Zhou, X.; Zhang, C.; Zhang, M.; Feng, A.; Qu, S.L.; Zhang, Y.; Liu, X.; Jia, Z.; Wu, G. Synthesis of Fe $\mathrm{O}_{4} /$ carbon foams com-posites with broadened bandwidth and excellent electromagnetic wave absorption performance. Compos. Part A Appl. Sci. Manuf. 2019, 127, 105627. [CrossRef]

41. Li, X.; Xu, Y.; Wu, H.; Qian, X.; Chen, L.; Dan, Y.; Yu, Q. Porous $\mathrm{Fe}_{3} \mathrm{O}_{4} / \mathrm{C}$ nanoaggregates by the carbon polyhedrons as tem-plates derived from metal organic framework as battery type materials for supercapacitors. Electrochim. Acta 2020, 337, 135818. [CrossRef]

42. Cao, Z.; Ma, X. Encapsulated $\mathrm{Fe}_{3} \mathrm{O}_{4}$ into tubular mesoporous carbon as a superior performance anode material for lithium-ion batteries. J. Alloys Compd. 2020, 815, 152542. [CrossRef]

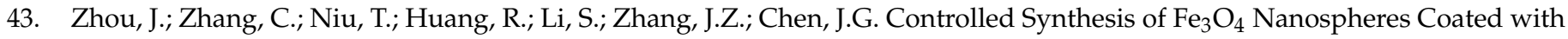
Nitrogen-Doped Carbon for High Performance Supercapacitors. ACS Appl. Energy Mater. 2018, 1, 4599-4605. [CrossRef]

44. Lee, J.S.; Shin, D.H.; Jun, J.; Lee, C.; Jang, J. $\mathrm{Fe}_{3} \mathrm{O}_{4} /$ Carbon Hybrid Nanoparticle Electrodes for High-Capacity Electrochemical Capacitors. ChemSusChem 2014, 7, 1676-1683. [CrossRef] [PubMed]

45. Luo, X.-Y.; Chen, Y.; Mo, Y. A review of charge storage in porous carbon-based supercapacitors. New Carbon Mater. 2021, 36, 49-68. [CrossRef]

46. Kang, N.; Ji, L.; Zhao, J.; Zhou, X.; Weng, X.; Li, H.; Zhang, X.; Yang, F. Uniform growth of $\mathrm{Fe}_{3} \mathrm{O}_{4}$ nanocubes on the single-walled carbon nanotubes as an electrosensor of organic dyes and the study on its catalytic mechanism. J. Electroanal. Chem. 2019, 833, 70-78. [CrossRef] 
47. Liu, X.; Tian, J.; Li, Y.; Sun, N.; Mi, S.; Xie, Y.; Chen, Z. Enhanced dyes adsorption from wastewater via $\mathrm{Fe}_{3} \mathrm{O}_{4}$ nanopar-ticles functionalized activated carbon. J. Hazard. Mater. 2019, 373, 397-407. [CrossRef] [PubMed]

48. Liu, H.; Jia, M.; Zhu, Q.; Cao, B.; Chen, R.; Wang, Y.; Wu, F.; Xu, B. 3D-0D Graphene-Fe ${ }_{3} \mathrm{O}_{4}$ Quantum Dot Hybrids as HighPerformance Anode Materials for Sodium-Ion Batteries. ACS Appl. Mater. Interfaces 2016, 8, 26878-26885. [CrossRef]

49. Wang, L.; Yu, J.; Dong, X.; Li, X.; Xie, Y.; Chen, S.; Li, P.; Hou, H.; Song, Y. Three-Dimensional Macroporous Carbon/Fe 3 O ${ }_{4}-D_{0}$ Ped Porous Carbon Nanorods for High-Performance Supercapacitor. ACS Sustain. Chem. Eng. 2015, 4, 1531-1537. [CrossRef]

50. Yan, J.; Leng, Y.C.; Guo, Y.; Wang, G.; Gong, H.; Guo, P.; Tan, P.; Long, Y.Z.; Liu, X.; Han, W. Highly conductive graphene paper with vertically aligned reduced graphene oxide sheets fabricated by improved electrospray deposition technique. ACS Appl. Mater. Interfaces 2019, 11, 10810-10817. [CrossRef] [PubMed]

51. Sun, F.; Wang, H.; Qu, Z.; Wang, K.; Wang, L.; Gao, J.; Gao, J.; Liu, S.; Lu, Y. Carboxyl dominant oxygen rich carbon for im-proved sodium ion storage: Synergistic enhancement of adsorption and intercalation mechanisms. ACS Appl. Eenergy Mater. 2021, 11, 2002981.

52. Sun, F.; Qu, Z.; Gao, J.; Wu, H.B.; Liu, F.; Han, R.; Wang, L.; Pei, T.; Zhao, G.; Lu, Y. In situ doping boron atoms into porous carbon nanoparticles with increased oxygen graft enhances both affinity and durability toward electrolyte for greatly improved super-capacitive performance. Adv. Funct. Mater. 2018, 28, 1804190-1804200. [CrossRef]

53. Li, Z.N.; Gadipelli, S.; Li, H.C.; Howard, C.A.; Brett, D.J.L.; Shearing, P.R.; Guo, Z.; Parkin, I.P.; Li, F. Tuning the interlayer spacing of graphene laminate films for efficient pore utilization towards compact capacitive energy storage. Nat. Energy 2020, 5, 160-168. [CrossRef]

54. Li, X.R.; Jiang, Y.H.; Wang, P.Z.; Mo, Y.; Lai, W.D.; Li, Z.J.; Yu, R.J.; Du, Y.T.; Zhang, X.R.; Chen, Y. Effect of the oxygen functional groups of activated carbon on its electrochemical performance for supercapacitors. N. Carbon Mater. 2020, 35, 232-243. [CrossRef]

55. Fan, H.; Niu, R.; Duan, J.; Liu, W.; Shen, W. Fe $\mathrm{O}_{4} @$ Carbon Nanosheets for All-Solid-State Supercapacitor Electrodes. ACS Appl. Mater. Interfaces 2016, 8, 19475-19483. [CrossRef] [PubMed]

56. Nawwar, M.; Poon, R.; Chen, R.; Sahu, R.P.; Puri, I.K.; Zhitomirsky, I. High areal capacitance of $\mathrm{Fe}_{3} \mathrm{O}_{4}$-decorated carbon nanotubes for supercapacitor electrodes. Carbon Energy 2019, 1, 124-133. [CrossRef]

57. Sun, J.; Zan, P.; Yang, X.; Ye, L.; Zhao, L. Room-temperature synthesis of $\mathrm{Fe}_{3} \mathrm{O}_{4} / \mathrm{Fe}$-carbon nanocomposites with Fe-carbon double conductive network as supercapacitor. Electrochim. Acta 2016, 215, 483-491. [CrossRef]

58. Kumar, R.; Singh, R.K.; Vaz, A.R.; Savu, R.; Moshkalev, S.A. Self-Assembled and One-Step Synthesis of Interconnected 3D Network of $\mathrm{Fe}_{3} \mathrm{O}_{4}$ / Reduced Graphene Oxide Nanosheets Hybrid for High-Performance Supercapacitor Electrode. ACS Appl. Mater. Interfaces 2017, 9, 8880-8890. [CrossRef]

59. Jiao, L.; Wan, G.; Zhang, R.; Zhou, H.; Yu, S.; Jiang, H. From Metal organic frameworks to single atom Fe implanted N doped porous carbons: Efficient oxygen reduction in both alkaline and acidic media. Angew. Chem. Int. Ed. 2018, 57, 8525-8529. [CrossRef] [PubMed]

60. Yang, Y.; Yang, Y.; Pei, Z.; Wu, K.-H.; Tan, C.; Wang, H.; Wei, L.; Mahmood, A.; Yan, C.; Dong, J.; et al. Recent Progress of Carbon-Supported Single-Atom Catalysts for Energy Conversion and Storage. Matter 2020, 3, 1442-1476. [CrossRef]

61. Li, Q.-K.; Li, X.-F.; Zhang, G.; Jiang, J. Cooperative Spin Transition of Monodispersed FeN3 Sites within Graphene Induced by CO Adsorption. J. Am. Chem. Soc. 2018, 140, 15149-15152. [CrossRef] [PubMed]

62. Zhao, L.; Zhang, Y.; Huang, L.-B.; Liu, X.-Z.; Zhang, Q.-H.; He, C.; Wu, Z.-Y.; Zhang, L.-J.; Wu, J.; Yang, W.; et al. Cascade anchoring strategy for general mass production of high-loading single-atomic metal-nitrogen catalysts. Nat. Commun. 2019, 10, 1278. [CrossRef] [PubMed]

63. Zhang, Q.; Rong, J.; Peng, M.D.; Wei, B. The governing self-discharge processes in activated carbon fabric based superca-pacitors with different organic electrolytes. Energy Environ. Sci. 2011, 4, 2152. [CrossRef]

64. Xia, M.; Nie, J.; Zhang, Z.; Lu, X.; Wang, Z.L. Suppressing self-discharge of supercapacitors via electrorheological effect of liquid crystals. Nano Energy 2018, 47, 43-50. [CrossRef]

65. Ricketts, B.; Ton-That, C. Self-discharge of carbon-based supercapacitors with organic electrolytes. J. Power Sources 2000, 89, 64-69. [CrossRef] 